\title{
Cerebral autosomal dominant arteriopathy with subcortical infarcts and leukoencephalopathy in an Israeli family
}

This article was published in the following Dove Press journal:

Neuropsychiatric Disease and Treatment

17 June 2011

Number of times this article has been viewed

\author{
Radi Shahien' \\ Silvia Bianchi ${ }^{2}$ \\ Abdalla Bowirrat' \\ 'Department of Neurology, \\ Ziv Medical Center, Safed, Israel; \\ ${ }^{2}$ Department of Neurological and \\ Behavioral Sciences, University of \\ Siena, Viale Bracci, Siena, Italy
}

Correspondence: Abdalla Bowirrat Department of Neurology,

Ziv Medical Center, Zfat I 3 I00, Israel

Tel +97246828927

Fax +972 46828648

Email prof.bowirrat@yahoo.com

\begin{abstract}
Cerebral autosomal-dominant arteriopathy with subcortical infarcts and leukoencephalopathy (CADASIL) is the most common monogenic form of hereditary cerebral microangiopathy, and is caused by over 170 different mutations in the NOTCH3 gene at locus 19p13.1-13.26. We report the first study of familial CADASIL in a 39-year-old Jewish woman and her mother who had died previously. The patient's investigations revealed a normal hemogram with no vascular risk factors or chronic disease. Lumbar puncture was normal. Cranial computed tomography scan revealed bilateral diffuse hypodensities in the subcortical white matter. Cranial magnetic resonance imaging showed hyperintense lesions in the cerebral white matter on T2-weighted images. On electron microscopy, a characteristic granular osmiophilic material was seen in the basement membrane surrounding the pericytes and smooth muscle cells in small-sized and medium-sized vessels. Molecular analysis of the NOTCH3 gene was performed with automatic sequencing of exon 3 and 4 (and intron-exon boundaries) showing a nucleotide c.268C $>\mathrm{T}$ substitution, leading to a pathogenic amino acid substitution of p.Arg90Cys, confirming a diagnosis of CADASIL. This mutation was also found in the patient's mother. Although the exact prevalence of CADASIL is not known, this disorder has been reported worldwide, and now including Jews, with a genotype and clinical phenotype similar to that in other ethnic groups.
\end{abstract}

Keywords: CADASIL, autosomal-dominant inheritance, genetic diagnostics, NOTCH3, arteriopathy

\section{Introduction}

The NOTCH signaling pathway system is present in most multicellular organisms for cell-cell communication, and involves gene regulation mechanisms that control multiple cell differentiation processes during embryonic and adult life. Indeed, it is an evolutionarily conserved, intercellular signaling system that plays a crucial role during intrauterine vascular and physiological development, contributing to cell destiny in many different tissues. NOTCH signals control how cells respond to intrinsic or extrinsic developmental stimuli and are necessary to trigger specific developmental programs. In addition, NOTCH activity affects the implementation of differentiation, proliferation, and apoptotic programs, serving as a general developmental tool which influences organ formation and morphogenesis in all metazoan organisms in the animal kingdom. ${ }^{1,2}$ The name NOTCH (a V-shaped cut) derives from a concavity occurring in the wing of Drosophila melanogaster (fruit fly), which carries only one functioning copy of the gene. ${ }^{3}$ 
Genes of the NOTCH family encode large single-pass transmembrane proteins. The NOTCH receptor is a heterooligomer composed of a large extracellular portion and a small intracellular region. ${ }^{4}$

In mammals, four NOTCH receptors (NOTCH1NOTCH4) and five structurally similar NOTCH ligands (Delta-like1 [also called Delta-1], Delta-3, Delta-4, Jagged1, and Jagged2) have been identified. ${ }^{5-8}$

The extracellular domain of NOTCH family proteins contains a large number of tandem repeat copies of an epidermal growth factor-like motif. ${ }^{9}$ Mutations in genes encoding NOTCH pathway components underlie three inherited human diseases, ie, Alagille syndrome, spondylocostal dysostosis, and cerebral autosomal dominant arteriopathy with subcortical infarcts and leukoencephalopathy (CADASIL). ${ }^{10-16}$

The latter is the most common monogenic form of hereditary cerebral angiopathy, and is caused by over 170 different mutations in the NOTCH3 gene at chromosome $19,{ }^{17-19}$ which shows considerable genetic heterogeneity. ${ }^{20,21}$

In 1996, Joute et al identified a human gene mutation in NOTCH3 (NOTCH homolog 3, Drosophila) as the malfunctioning gene causing CADASIL pathology.22 The human NOTCH3 gene was mapped to chromosome 19q13.1-13.26, where the gene causing CADASIL was also located. ${ }^{23}$ The NOTCH3 gene consists of 33 exons spanning roughly $7 \mathrm{~kb}$ and encodes a transmembrane protein comprising 2321 amino acids. $^{24}$

CADASIL is an adult-onset inherited cerebrovascular disease characterized by recurrent strokes and progressive dementia, with or without migraine-like headaches, seizures, pseudobulbar palsy, and depression. ${ }^{25-27}$ Absence of hypertension or other known vascular risk factors is essential for the clinical diagnosis..$^{14,28,29}$

CADASIL shows true dominancy, and the vast majority of CADASIL mutations (95\%) are missense mutations removing or inserting cysteine residues within 1-34 epidermal growth factor-like repeats in the NOTCH3 protein. Small inframe deletions are observed and splice-site mutations in the NOTCH3 gene encoding a transmembrane receptor are also seen, which invariably cause inframe deletions resulting in loss of cysteine residues. ${ }^{30-34}$

Indeed, six pathogenic deletions, one combined deletion and insertion (or two adjacent nucleotide substitutions), two duplications, and two splice-site mutations have been described. In addition to these common types of cysteineaffecting CADASIL mutations, seven mutations not altering the number of cysteines have been reported. One of these mutations is a deletion which removes the amino acids between two cysteines, and the remainder are missense mutations leading to one amino acid substitution. . $19,19,22,30,32^{2}$ Whether these substitutions are truly pathogenic mutations or merely polymorphisms is as yet unclear. So far, only three reports of patients homozygous for pathogenic NOTCH3 mutations have been published. ${ }^{35-37}$ In addition, two confirmed de novo mutations in CADASIL patients have been reported. ${ }^{38,39}$ Thus, either a cysteine residue is deleted or altered to another amino acid residue or, conversely, mutations of noncysteine residues lead to introduction of novel cysteine residues. ${ }^{32}$ This results in an uneven number of cysteine residues in the given domain, most likely modifying the tertiary structure of the protein. ${ }^{31}$

At least three mechanisms mediate the pathogenic effects of NOTCH3 mutation in CADASIL, ie, loss of receptor function, gain of function, and neomorphic (eg, toxic) processes. Mutations of NOTCH3 characteristically lead to an epidermal growth factor-like repeat domain (six repeats in the normal domain) and an odd number of cysteine residues (either five or seven) through gain or loss of a residue. ${ }^{22}$ No mutations leading to three cysteine residues or not involving a cysteine residue have ever been reported..$^{31,40}$ However, it is not yet known whether these mutations primarily affect receptor trafficking, maturation, and/or signaling. ${ }^{41}$

Historically, on the basis of thorough scrutiny of the literature, the first CADASIL family is now believed to have been reported in 1955 by Van Bogaert, ${ }^{42,43}$ who described two sisters with rapidly progressive subcortical encephalopathy of Binswanger's type. ${ }^{44}$ In 1977, Sourander and Walinder reported a Swedish family with a CADASIL mutation and multi-infarct dementia of autosomal-dominant inheritance, presenting with pyramidal, bulbar, and cerebellar symptoms, a relapsing course, and gradually evolving severe dementia. ${ }^{28}$ In 2007, Low et al verified that the hereditary multi-infarct dementia in the Swedish family reported by Sourander and Walinder was erroneously attributed to CADASIL, and that the patients did not show the characteristic features of CADASIL on pathological examination. ${ }^{45}$ In Finland, the first family with CADASIL was identified and published as hereditary multi-infarct dementia in $1987 .{ }^{46}$ After the gene test became available, 15 new families comprising approximately 100 patients or presymptomatic carriers of the gene defect have been identified in Finland. Fourteen of the 15 families identified in Finland carry the same C475T transition mutation of the NOTCH3 gene, which leads to substitution of the 133 arginine by cysteine (R133C). ${ }^{19,27,46}$ Information concerning the exact global incidence and prevalence of CADASIL is limited. In the west of Scotland, the prevalence 
of confirmed CADASIL cases in 2004 was 1.98/100,000 and the estimated prevalence based on pedigree information was $4.15 / 100,000 .{ }^{46}$ In Finland, a similar prevalence has been estimated..$^{48,49}$

In 1993, Tournier-Lasserve et al applied linkage analysis to two large unrelated French families presenting with CADASIL (using the acronym CADASIL for the first time), and localized the disease to chromosome 19q12. ${ }^{14}$ A more recent study by Tikka et al ${ }^{17}$ investigated different pathogenic mutations in 34 patients in France, and demonstrated three novel point mutations (p.Cys67Ser, p.Cys251Tyr, and p.Tyr1069Cys) and a novel duplication (p.Glu434-Leu436dup). In this cohort, the congruence between NOTCH3 mutations and deposition of granular osmiophilic material around vascular smooth muscle cells, which is the gold standard for confirmation of a diagnosis of CADASIL, was $100 \% .^{17}$

In 2002, Markus et al performed a large genetic study of 48 British families and showed that most mutations of CADASIL were located in exon 4 , followed by exons $3,5,6$, 8,18 , and $22 .{ }^{50}$ Another study from a Dutch DNA diagnostic laboratory (44 Dutch and 22 foreign families) also found the mutation rate of CADASIL was highest in exon 4, followed by exon $3,5,6,11$, and $19 .{ }^{51}$ Thus, it is suggested that exons 3-6 should be screened first, and then exons 11 and 18-23. In fact, geographic variations have been described, showing exon 3 to be the second most common mutation site in French, British, and German individuals, ${ }^{32,50-52}$ while exon 11 frequently harbors mutations in affected Dutch individuals. $^{51}$

Epidemiologically, the precise frequency and mortality rate of CADASIL worldwide is still unknown. The mean age at death has been reported to be 61 years after a mean disease duration of approximately 23 years. ${ }^{53}$ Men tend to die earlier than women, ${ }^{19}$ but mortality appears to be equally distributed between the genders, and the onset of clinical symptoms usually occurs in the fourth decade of life, with a mean age at presentation of 46.1 years. ${ }^{18,53}$ Fewer than half of patients older than 60 years can walk without assistance. ${ }^{54}$ Nearly $80 \%$ of patients are completely dependent immediately before death. ${ }^{19}$ However, the number of reported cases of CADASIL is gradually increasing as the clinical picture becomes more widely recognized and genetic testing becomes available.

CADASIL occurs worldwide and has been reported in many ethnic groups. So far, most of the CADASIL patients have been found in Caucasian families, including France, Germany, the UK, Finland, Sweden, Italy, and the Netherlands. ${ }^{15,19,49,50,53,55-59}$ Reports from North America are relatively sparse, despite the high level of academic activity in this region, while the numbers of reported cases and spectrum of mutations are relatively low in Asia, ${ }^{60,61}$ but may reflect an underestimation of the prevalence of CADASIL in Asian populations.

In 2007, Bohlega et $\mathrm{al}^{62}$ studied three families from Arab countries (Saudi Arabia, Kuwait, and Yemen) containing 19 individuals affected by CADASIL. All NOTCH3 exons were screened for mutations, which revealed the presence of previously reported mutations in c.406C $>\mathrm{T}$ (p.Arg110 > Cys) in two families from Saudi Arabia and Kuwait, and a c. $475 \mathrm{C}>\mathrm{T}$ (p.Arg133 > Cys) mutation in the family from Yemen. The investigators concluded that CADASIL does occur in Arabs, with a clinical phenotype and genotype similar to that in other ethnic groups.

Clinically, CADASIL, albeit heterogeneous, is associated with recurrent stroke (cerebral infarcts) in $70 \%-80 \%$ of cases, almost exclusively lacunar infarcts involving the subcortical white matter, deep gray matter nuclei, and brain stem, as well as progressive cognitive impairment (subcortical dementia with pseudobulbar palsy and urinary incontinence) in 30\%-50\% of cases are the main clinical manifestations of CADASIL. Additional neurological manifestations include migraine with aura and stroke. ${ }^{63}$ In most clinical studies of CADASIL, patients are documented to suffer from migraine or recurrent headaches; different studies report occurrence of migraine in $22 \%-64 \%$ of patients. ${ }^{15}$ Migraine is usually the first symptom, with the mean age of onset in the late twenties. ${ }^{25,64-68}$ CADASIL migraine is typically associated with aura. Most often the aura is characteristic, ie, symptoms are visual, sensory, aphasic, or have motor features, and may also appear in various combinations.

Generally, the first stroke appears at the age of 35-45 years. ${ }^{69}$ Strokes are caused by small infarcts, which result from fibrosis and obliteration of the lumen and destruction of smooth muscle cells in the walls of the cerebral arteries. Recurrent infarcts, mainly in the cerebral white matter and deep gray matter, lead to cognitive decline and ultimately dementia. ${ }^{15,53}$ Ischemic manifestations of the optic nerve and mood disturbance occur in $30 \%$ of cases. However, there is considerable discrepancy between individuals regarding the severity of the phenotype. ${ }^{15,19,53}$

The pathological hallmark of CADASIL is profound demyelination and axonal damage, as well as arteriopathy involving distinctive degeneration of the arterial smooth muscle cells in the brain and peripheral organs. Magnetic resonance imaging (MRI) has enabled quantification of the burden of leukoaraiosis and lacunar infarction in the 
subcortical structures. Hyperintensities in the deep white matter, internal and external capsules, and anterior temporal pole are characteristic of CADASIL. Increased MRI signals in the anterior temporal pole are suggested to be diagnostic for CADASIL with $90 \%$ sensitivity and 100\% specificity. White matter impairment and lacunar infarcts can also be seen as hypointensities on T1-weighted MRI and computed tomography $(\mathrm{CT}){ }^{48}$

\section{Familial case report of CADASIL in Israel}

We report the history of the first Israeli family identified to have CADASIL, comprising a 39-year-old woman and her mother who had died as a consequence of CADASIL three years earlier. The patient presented with complaints of migrainous headache with aura (for five years), mild cognitive impairment (for four years), and dysarthria (for two years). In addition, she suffered from vomiting, dizziness, blurred vision, photophobia, and numbness on the left side two days before her admission to our department in October 2010. In 2007, she had weakness of both lower limbs, more on the left than on the right side. On admission, her investigations revealed a normal hemogram and no vascular risk factors, eg, hypertension, diabetes, or hypercholesterolemia, except for moderate triglyceride levels. Lumbar puncture showed no abnormality. Cranial CT scan with and without contrast revealed diffuse bilateral hypodensities throughout the subcortical white matter. Five months later (Figure 1), she became mildly forgetful. Cranial MRI done at this time showed multiple hyperintense periventricular white matter

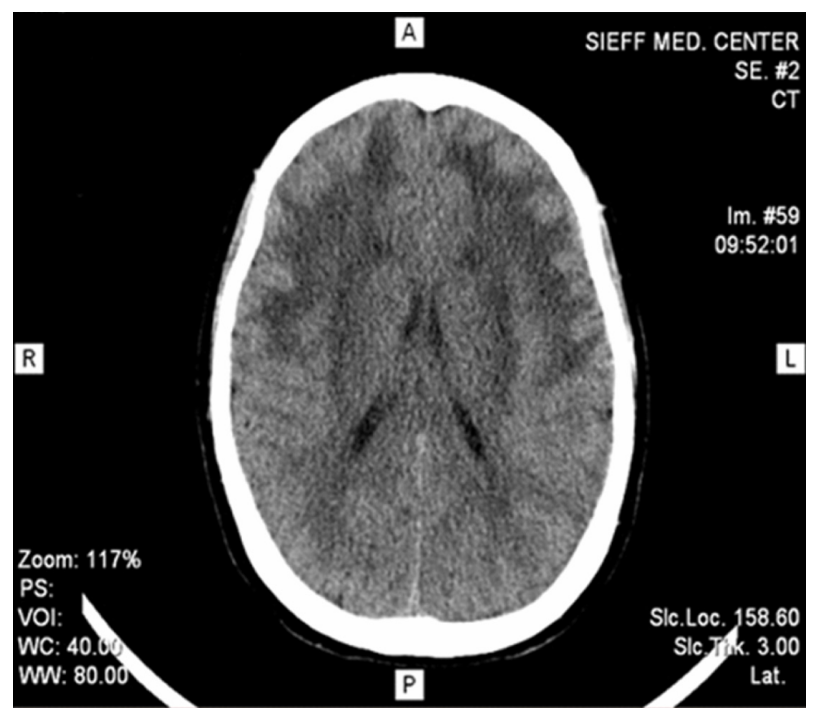

Figure I Cranial computed tomography scan revealed bilateral diffuse hypodensities over the subcortical white matter. lesions on T2-weighted images (Figures 2, 3, and 4). Carotid Doppler studies as well as visual and brainstem evoked potentials were normal.

Considering neurodemyelinating disease as an underlying pathology, she was given methylprednisolone. Her condition continued to deteriorate progressively. Dysarthria became more apparent, and left lower motor neuron dysfunction and intermittent diplopia were observed. She had mild spastic weakness in all four limbs. Tendon jerks were brisk and plantar responses were extensor. There was no sensory deficit and there were no cerebellar signs. On cognitive examination, the patient cooperated satisfactorily in spite of her spastic dysarthria and had a score of 19/30 on minimental state examination. Examination of other systems was normal.

The patient's pedigree chart is shown in Figure 6. Her mother had had a history of seven years of subcortical dementia of unknown etiology, dysarthria, multiple ischemic changes, and white matter hypodensities on brain CT scan (Figure 5), prior to her death in 2007.

Our patient's repeat brain MRI done more recently revealed confluent and discrete, fairly symmetric, T2 hyperintense foci in the deep and subcortical white matter of both cerebral hemispheres. Similar foci were present in the brainstem, thalami, basal ganglia, and subcortical white matter of the anterior temporal lobes. Considering the

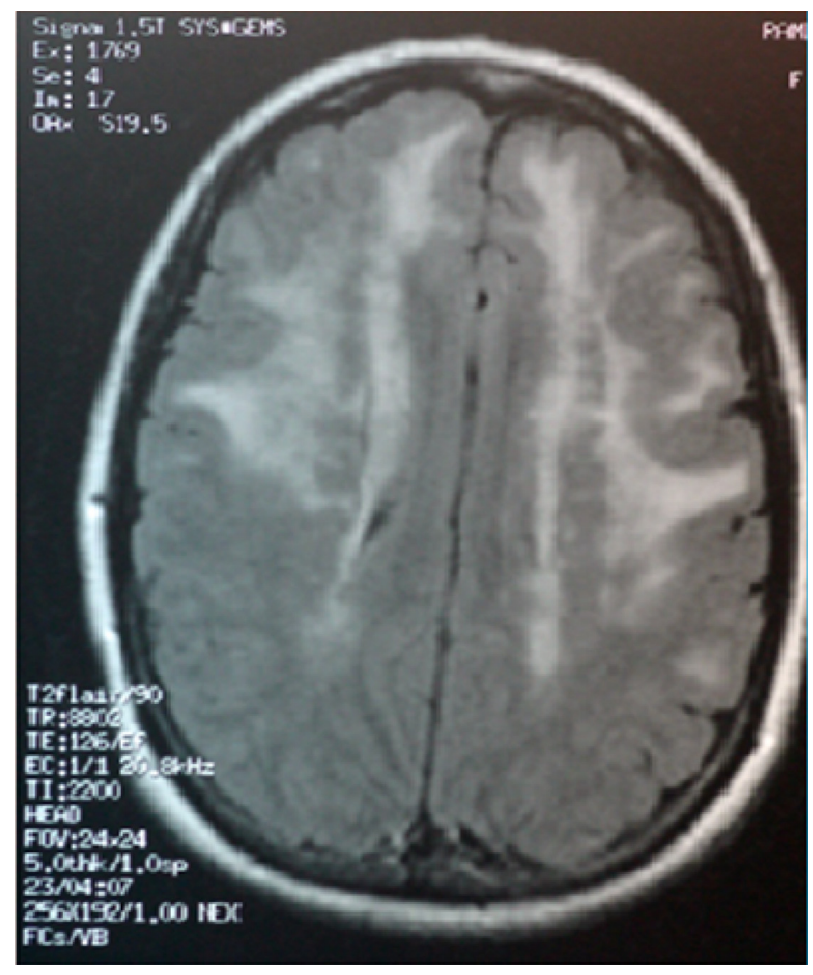

Figure 2 Magnetic resonance imaging scan of the brain (sagital section) showing hyperintensities involving white matter. 


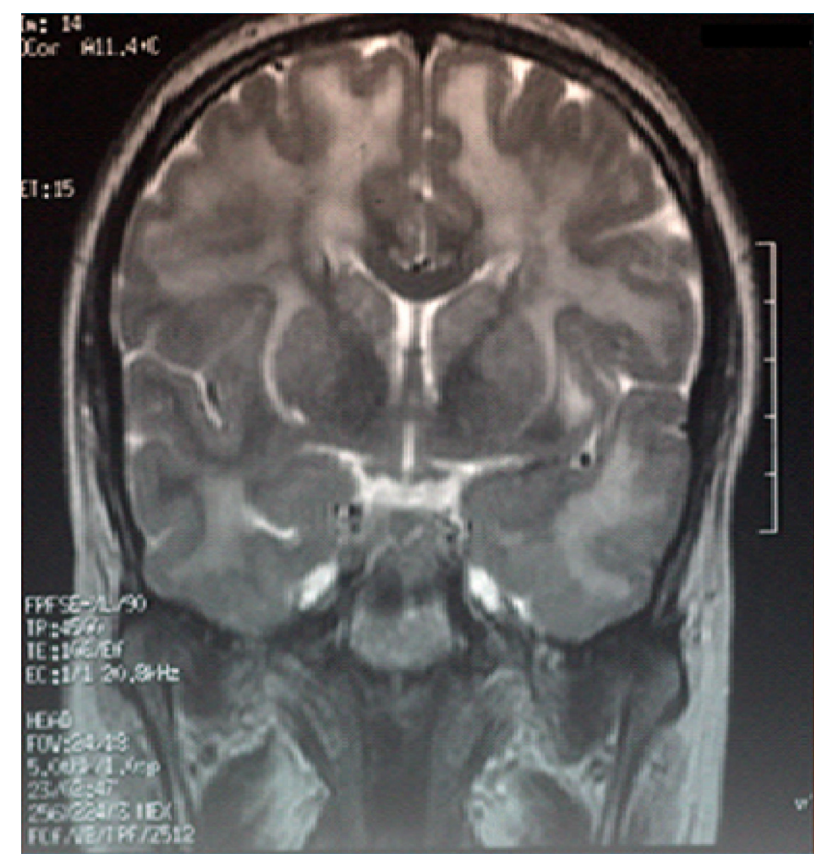

Figure 3 Magnetic resonance imaging scan of the brain (coronal section) showing hyperintensities involving white matter.

possibility of CADASIL, a skin biopsy was analyzed by electron microscopy, and a molecular analysis for the gene defect was done by sequencing the polymerase chain reaction products of exons 3 and 4 of the NOTCH3 gene. The skin biopsy revealed characteristic granular osmiophilic material within the basement membrane surrounding the pericytes and smooth muscle cells of the small-sized and mediumsized vessels (Figure 7). In addition, molecular analysis

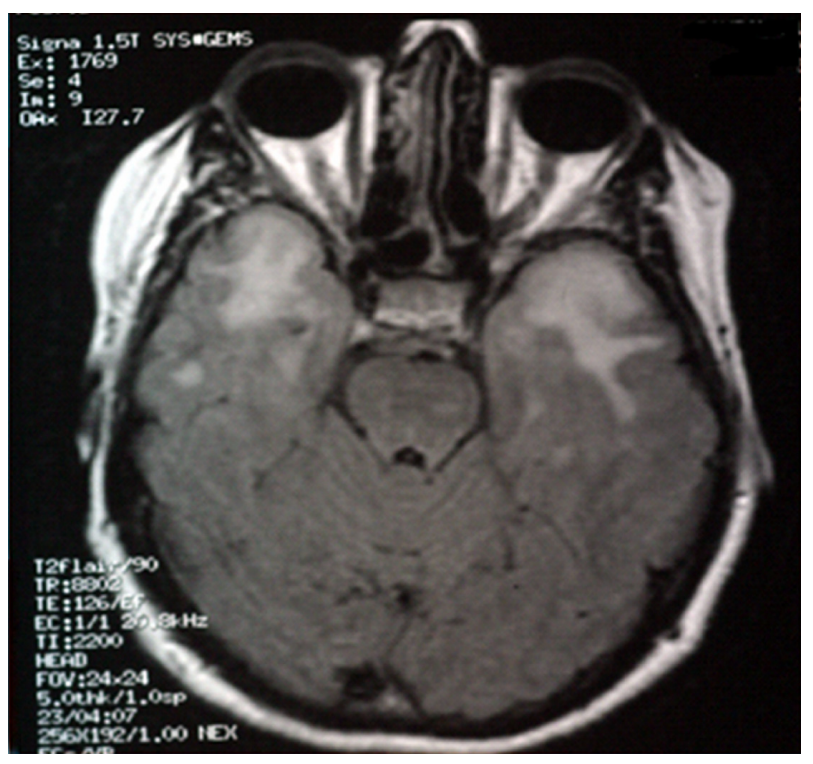

Figure 4 Magnetic resonance imaging scan of the brain showing hyperintensities involving the temporal poles in the patient with cerebal autosomal dominant arteriopathy with subcortical infarcts and leuoencephalopathy.

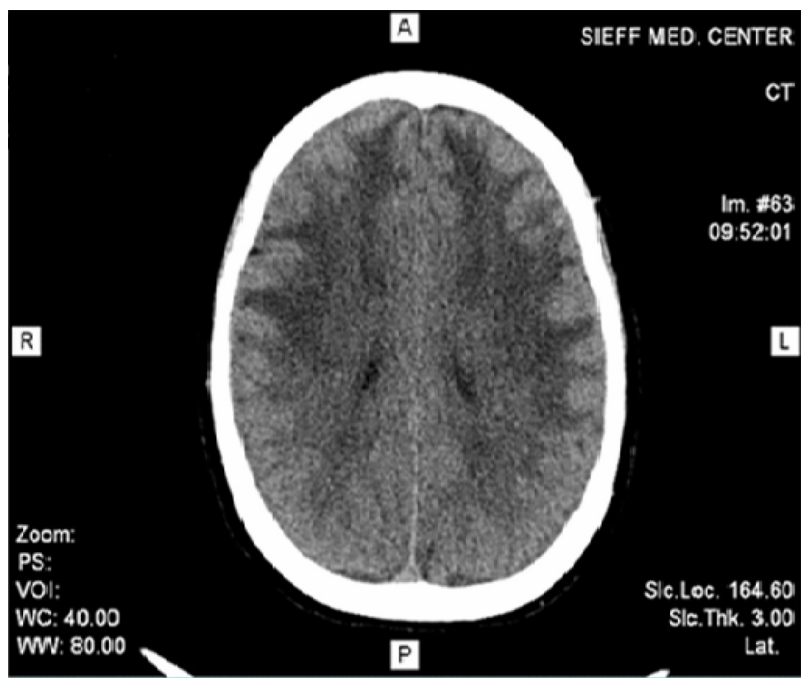

Figure 5 Mother's cranial computed tomography scan (2007) showing multiple ischemic changes and white matter hyperdensities.

of the NOTCH3 gene showed a nucleotide substitution at c.268C $>$ T, leading to a pathogenic amino acid substitution of p.Arg90Cys, confirming a diagnosis of CADASIL. These findings were similar to the NOTCH3 gene mutation and brain biopsy findings for the patient's mother, which were re-examined recently. To our knowledge, this is the first familial case of CADASIL to be reported in the Israeli population.

\section{Discussion}

CADASIL is the most common form of hereditary subcortical vascular dementia. It is caused by a defective NOTCH3 gene, and over 170 different mutations are known. The main clinical features are migraine with aura (often atypical or isolated),

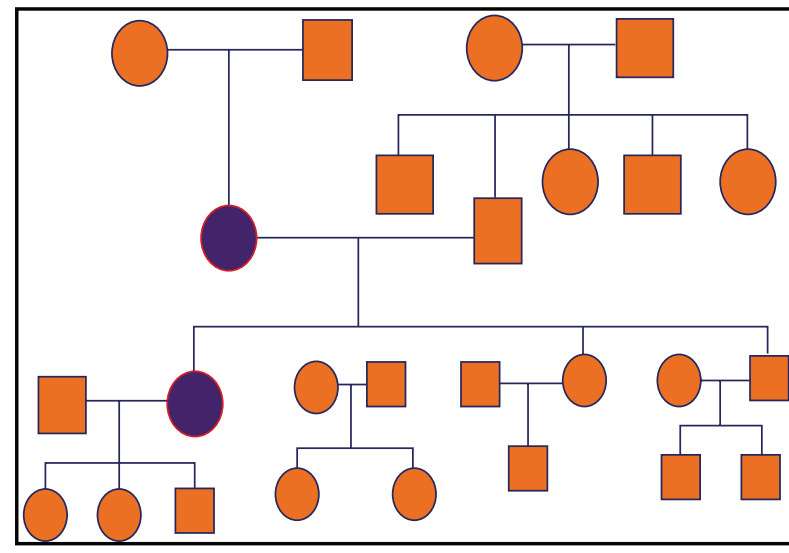

CADASIL

Figure 6 Pedigree of the family with cerebal autosomal dominant arteriopathy with subcortical infarcts and leuoencephalopathy (CADASIL). 


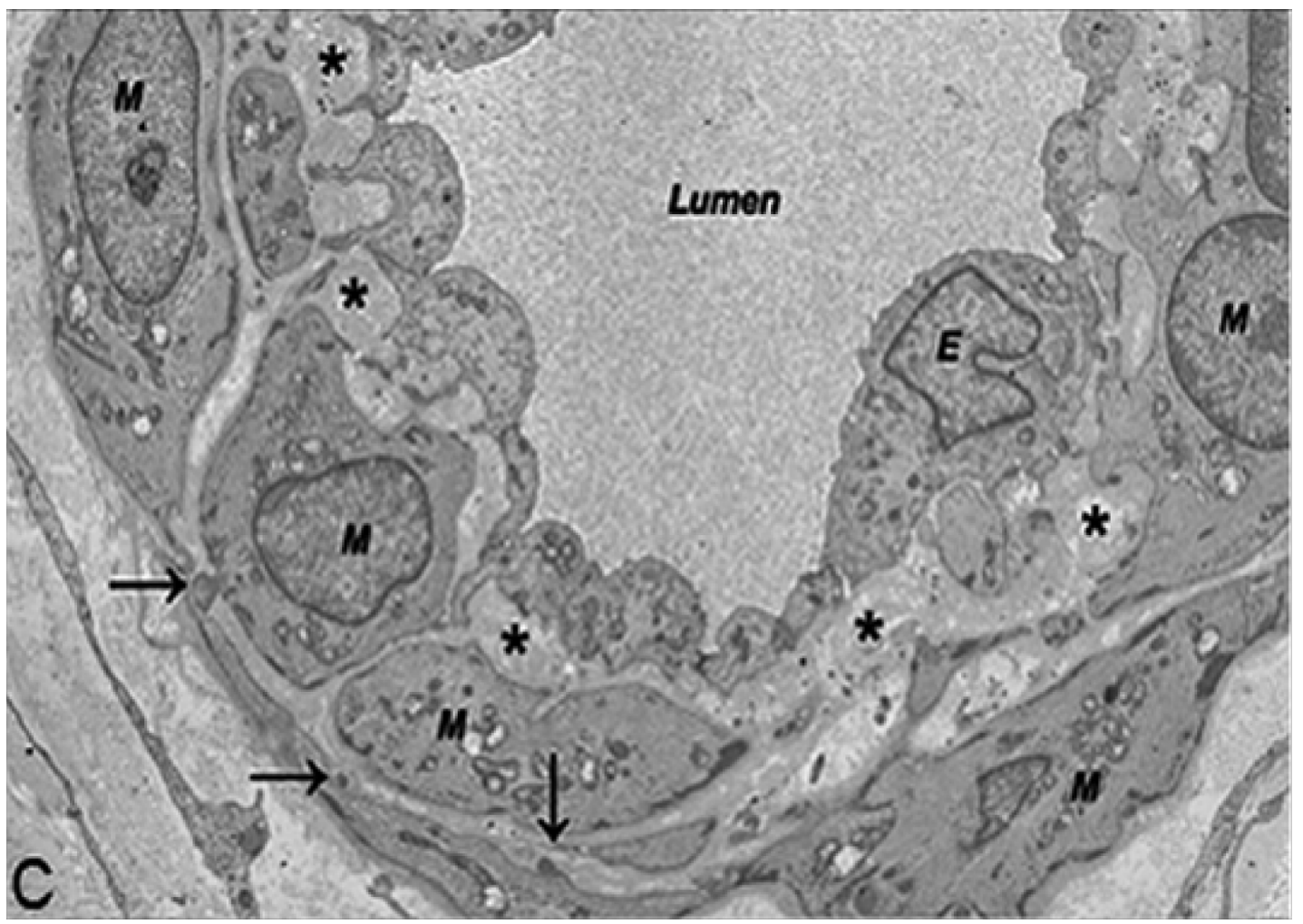

Figure 7 Pathological changes in the capillary: capillary with granular osmiophilic material deposit located in pericyte infolding and thickened basement membrane showing collagen fibrils. In addition, endothelial cells are thin.

strokes, cognitive decline, dementia, and psychiatric symptoms. Executive and organizing cognitive functions are impaired first, and memory is affected later. Typical MRI findings are T2-weighted hyperintensities in the temporopolar white matter and the capsula externa. Smooth muscle cells in the small arteries throughout the body degenerate and vessel walls become fibrotic. In the brain, this results in circulatory disturbances and lacunar infarcts, mainly in the cerebral white matter and deep gray matter. The exact pathogenesis is still open. A dominant-negative toxic effect is suggested, possibly related to NOTCH3 misfolding. The diagnosis is made either by identifying a pathogenic $\mathrm{NOTCH} 3$ mutation or by electron microscopic demonstration of granular osmiophilic material in a skin biopsy.

In this familial study, we describe the clinical and neuropsychological features, as well as MRI and skin biopsy findings in two Israeli CADASIL patients carrying c. $268 \mathrm{C}>\mathrm{T}$ mutation in the NOTCH3 gene on chromosome 19. Molecular analysis of the NOTCH3 gene mutation was performed by automatic sequencing of exon 3 and 4 (and intron-exon boundaries) which shows the nucleotide substitution c.268C $>$ T, leading to a pathogenic amino acid substitution, ie, p.Arg90Cys, confirming the diagnosis of CADASIL.
Findings were similar for the patient's mother. Reports from other countries were compared, and were similar to ours. Two Chinese families with previously reported NOTCH3 gene mutations, ie, c. $397 \mathrm{C}>\mathrm{T}$ and c. $268 \mathrm{C}>\mathrm{T}$, were identified, ${ }^{70}$ and another family report from Iran showed the pathogenic amino acid substitution of $\mathrm{p}$.Arg90Cys, confirming a diagnosis of CADASIL. ${ }^{71}$ In addition, two Swedish families from Värmlan were also identified to be carrying the same mutation as our case, ie, p.Arg90Cys. ${ }^{72}$

Given the unknown frequency of CADASIL worldwide, which may reflect misdiagnosis, or more probably underdiagnosis, the purposes of this report are to highlight that CADASIL also exists in the Israel population, with a genotype and clinical phenotype similar to that of other ethnic groups, and to underscore the importance of genetic analysis in patients who present with subcortical strokes whenever the MRI scan reveals significant white matter changes. We also wish to raise clinical suspicion of this clinical entity based on the presence of a clear family history in the context of typical clinical, genetic, and radiological findings. We also suggest that screening for mutations in the NOTCH3 gene be considered as a diagnostic test for CADASIL. The test would involve two steps, ie, initial screening of exons 3 and 4 , 
and only if no mutations are present, the remaining 31 exons should be analyzed. Taken together, clinical, pathological, radiological, and molecular studies should make the diagnosis straightforward.

\section{Acknowledgment}

The authors thank Professor Maria Teresa Dotti for her contribution to this research.

\section{Disclosure}

The authors report no conflicts of interest in this work.

\section{References}

1. Artavanis-Tsakonas S, Rand MD, Lake RJ. NOTCH signaling: cell fate control and signal integration in development. Science. 1999;284: 770-776.

2. Belin de Chantemèle EJ, Retailleau K, Pindaud F, et al. NOTCH3 is a major regulator of vascular tone in cerebral and tail resistance arteries. Arterioscler Thromb Vasc Biol. 2008;28:2216-2224.

3. Uyguner ZO, Siva A, Kayserili H, et al. The R110C mutation in NOTCH3 causes variable clinical features in two Turkish families with CADASIL syndrome. J Neurol Sci. 2006;246:123-130.

4. Brou C, Logeat F, Gupta N, et al. A novel proteolytic cleavage involved in notch signaling: the role of the disintegrin-metalloprotease TACE. Mol Cell. 2000;5:207-216.

5. Ladi E, Nichols JT, Ge W, et al. The divergent DSL ligand D113 does not activate NOTCH signaling but cell autonomously attenuates signaling induced by other DSL ligands. J Cell Biol. 2005;170:983-992.

6. Fleming RJ. Structural conservation of NOTCH receptors and ligands. Semin Cell Dev Biol. 1998;9:599-607.

7. Yoon K, Gaiano N. NOTCH signaling in the mammalian central nervous system: insights from mouse mutants. Nat Neurosci. 2005;8:1411.

8. Shawber CJ, Kitajewski J. NOTCH function in the vasculature: insights from zebrafish, mouse and man. Bioessays. 2004;26:225-234.

9. Gridley T. NOTCH signaling and inherited disease syndromes. Hum Mol Genet. 2003;12:R9-R13.

10. Krantz ID, Piccoli DA, Spinner NB. Alagille syndrome. J Med Genet. 1997;3:152-157.

11. Krantz ID. Alagille syndrome: chipping away at the tip of the iceberg. Am J Med Genet. 2002;112:160-162.

12. Mortier GR, Lachman RS, Bocian M, Rimoin DL. Multiple vertebral segmentation defects: analysis of 26 new patients and review of the literature. Am J Med Genet. 1996;61:310-319.

13. Turnpenny PD, Bulman MP, Frayling TM, et al. A gene for autosomal recessive spondylocostal dysostosis maps to 19q13.1-q13.3. Am J Hum Genet. 1999;65:175-182.

14. Tournier-Lasserve E, Joutel A, Melki J, et al. Cerebral autosomal dominant arteriopathy with subcortical infarcts and leukoencephalopathy maps to chromosome 19q12. Nat Genet. 1993;3:256-259.

15. Chabriat H, Vahedi K, Iba-Zizen MT, Joutel A, Nibbio A, Nagy TG. Clinical spectrum of CADASIL: a study of 7 families. Cerebral autosomal dominant arteriopathy with subcortical infarcts and leukoencephalopathy. Lancet. 1995;346:934-939.

16. Ruchoux MM, Guerouaou D, Vandenhaute B, Pruvo JP, Vermersch P, Leys D. Systemic vascular smooth muscle cell impairment in cerebral autosomal dominant arteriopathy with subcortical infarcts and leukoencephalopathy. Acta Neuropathol (Berl). 1995;89: $500-512$.

17. Tikka S, Mykkanen K, Ruchoux MM, Bergholm R, Junna M, Poyhonen M. Congruence between NOTCH3 mutations and GOM in 131 CADASIL patients. Brain. 2009;132:933-939.
18. Arboleda-Velasquez JF, Lopera F, Lopez E, et al. C455R NOTCH3 mutation in a Colombian CADASIL kindred with early onset of stroke. Neurology. 2002;59:277-279.

19. Opherk C, Peters N, Herzog J, Luedtke R, Dichgans M. Long-term prognosis and causes of death in CADASIL: a retrospective study in 411 patients. Brain. 2004;127:2533-2539.

20. Singhal S, Bevan S, Barrick T, et al. The influence of genetic and cardiovascular risk factors on the CADASIL phenotype. Brain. 2004;127: 2031-2038.

21. Federico A, Bianchi S, Dotti MT. The spectrum of mutations for CADASIL diagnosis. Neurol Sci. 2005;26:117-124.

22. Joutel A, Corpechot C, Ducros A, Vahedi K, Chabriat H, Mouton P. NOTCH3 mutations in CADASIL, a hereditary adult-onset condition causing stroke and dementia. Nature. 1996;383:707-710.

23. Larsson C, Lardelli M, White I, Lendahl U. The human NOTCH1, 2 , and 3 genes are located at chromosome positions 9q34, 1p13-p11, and 19p13.2-p13.1 in regions of neoplasia-associated translocation. Genomics. 1994;24:253-258.

24. Ungaro C, Mazzei R, Conforti FL, et al. Cadasil: extended polymorphisms and mutational analysis of the NOTCH3 gene. J Neurosci Res. 2009;87:1162-1167.

25. Menon S, Cox HC, Kuwahata M, et al. Association of a Notch 3 gene polymorphism with migraine susceptibility. Cephalalgia. 2011;31: 264-270.

26. Valenti R, Poggesi F, Pescini D, Inzitari LP. Psychiatric disturbances in CADASIL: a brief review. Acta Neurol Scand. 2008;118:291-295.

27. Chabriat H, Joutel A, Dichgans M, Tournier-Lasserve E, Bousser M-G. CADASIL. Lancet Neurol. 2009;8:643-653.

28. Sourander P, Walinder J. Hereditary multi-infarct dementia. Morphological and clinical studies of a new disease. Acta Neuropathol. 1977;39:247-254.

29. Stevens DL, Hewlett RH, Brownell B. Chronic familial vascular encephalopathy. Lancet. 1977;1:364-365.

30. Dichgans M, Ludwig H, Muller-Hocker J, Messerschmidt A, Gasser T. Small in-frame deletions and missense mutations in CADASIL: 3D models predict misfolding of NOTCH3 EGF-like repeat domains. Eur J Hum Genet. 2000;8:280-285.

31. Dichgans M, Herzog J, Gasser T. NOTCH3 in-frame deletion involving three cysteine residues in a family with typical CADASIL. Neurology. 2001;57:1714-1717.

32. Joutel A, Vahedi K, Corpechot C, et al. Strong clustering and stereotyped nature of NOTCH3 mutations in CADASIL patients. Lancet. 1997;350: 1511-1515.

33. Joutel A, Chabriat H, Vahedi K, et al. Splice site mutation causing a seven amino acid NOTCH3 in-frame deletion in CADASIL. Neurology. 2000;54:1874-1875.

34. Federico A, Bianchi S, Dotti MT. The spectrum of mutations for CADASIL diagnosis. Neurol Sci. 2005;26:117-124.

35. Tuominen S, Juvonen V, Amberla K, et al. Phenotype of a homozygous CADASIL patient in comparison to 9 age matched heterozygous patients with the same R133C NOTCH3 mutation. Stroke. 2001;32: 1767-1774.

36. Dotti MT, Bianchi S, De Stefano N, et al. Screening for CADASIL mutations in leukoencephalopathies. Neurology. 2003;60:A89.

37. Liem MK, Lesnik Oberstein SA, Vollebregt MJ, et al. Homozygosity for a NOTCH3 mutation in a 65-year-old CADASIL patient with mild symptoms: a family report. $J$ Neurol. 2009;255:1978-1980.

38. Joutel A, Dodick DD, Parisi JE, Cecillon M, Tournier-Lasserve E, Bousser MG. De novo mutation in the NOTCH3 gene causing CADASIL. Ann Neurol. 2000;47:388-391.

39. Coto E, Menendez M, Navarro R, Garcia-Castro M, Alvarez V. A new de novo NOTCH3 mutation causing CADASIL. Eur J Neurol. 2006;13: 628-631.

40. Kim Y, Cho EJ, Cho CG. Characteristics of CADASIL in Korea: a novel cysteine-sparing Notch3 mutation. Neurology. 2006;66: $1511-1516$ 
41. Karlström H, Beatus P, Dannaeus K, Chapman G, Lendahl U, Lundkvist J. A CADASILmutated NOTCH3 receptor exhibits impaired intracellular trafficking and maturation but normal ligand-induced signaling. Proc Natl Acad Sci U S A. 2002;99:17119-17124.

42. Davous P. CADASIL: a review with proposed diagnostic criteria. Eur J Neurol. 1998;5:219-233.

43. Bogaert V. Rapidly evolving progressive subcortical encephalopathy of Binswanger's type in two sisters. Med Hellen. 1955;24:961-972. French.

44. Bousser MG, Tournier-Lasserve E. Summary of the proceedings of the First International Workshop on CADASIL. Stroke. 1994;25: 704-707.

45. Low WC, Junna M, Borjesson-Hanson A, et al. Hereditary multiinfarct dementia of the Swedish type is a novel disorder different from NOTCH3 causing CADASIL. Brain. 2007;130:357-367.

46. Sonninen V, Savontaus M-L. Hereditary multi-infarct dementia. Eur Neurol. 1987;27:209-215.

47. Razvi SS, Davidson R, Bone I, Muir KW. The prevalence of cerebral autosomal dominant arteriopathy with subcortical infarcts and leucoencephalopathy (CADASIL) in the west of Scotland. J Neurol Neurosurg Psychiatry. 2005;76:739-741.

48. Kalimo H, Miao Q, Tikka S, et al. CAASIL: the most common hereditary subcortical vascular dementia. Future Neurol. 2008;3:683-704.

49. Mykkänen K, Savontaus ML, Juvonen V, et al. Detection of the founder effect in Finnish CADASIL families. Eur J Hum Genet. 2004;12: $813-819$.

50. Markus HS, Martin RJ, Simpson MA, et al. Diagnostic strategies in CADASIL. Neurology. 2002;59:1134-1138.

51. Oberstein SA. Diagnostic strategies in CADASIL. Neurology. 2003;60: 2020.

52. Peters N, Opherk C, Bergmann T, Castro M, Herzog J, Dichgans M. Spectrum of mutations in biopsy-proven CADASIL: implications for diagnostic strategies. Arch Neurol. 2005;62:1091-1094.

53. Dichgans M, Mayer M, Uttner I, Bruning R, Müller-Höcker J, Rungger $\mathrm{G}$. The phenotypic spectrum of CADASIL: clinical findings in 102 cases. Ann Neurol. 1998;44:731-739.

54. Meschia JF, Brott TG, Brown RD Jr. Genetics of cerebrovascular disorders. Mayo Clin Proc. 2005;80:122-132.

55. van den Boom R, Lesnik Oberstein SA, Ferrari MD, Haan J, van Buchem MA. Cerebral autosomal dominant arteriopathy with subcortical infarcts and leukoencephalopathy: MR imaging findings at different ages - 3rd-6th decades. Radiology. 2003;229:683-690.

56. Singhal S, Bevan S, Barrick T, Rich P, Markus HS. The influence of genetic and cardiovascular risk factors on the CADASIL phenotype. Brain. 2004;127:2031-2038.

57. Dotti MT, Federico A, Mazzei R, et al. The spectrum of NOTCH3 mutations in 28 Italian CADASIL families. J Neurol Neurosurg Psychiatry. 2005;76:736-738.
58. Pradotto L, Azan G, Doriguzzi C, Valentini C, Mauro A. Sporadic vascular dementia as clinical presentation of a new missense mutation within exon 7 of NOTCH3 gene. J Neurol Sci. 2008;271:207-210.

59. Stromillo ML, Dotti MT, Battaglini M. Structural and metabolic brain abnormalities in preclinical cerebral autosomal dominant arteriopathy with subcortical infarcts and leucoencephalopathy. J Neurol Neurosurg Psychiatry. 2009;80:41-47.

60. Tang SC, Lee MJ, Jeng JS, et al. Arg332Cys mutation of NOTCH3 gene in the first known Taiwanese family with cerebral autosomal dominant arteriopathy with subcortical infarcts and leukoencephalopathy. J Neurol Sci. 2005;228:125-128.

61. Tang S-C, Jeng J-S, Lee M-J, Yip P-K. NOTCH signaling and CADASIL. Acta Neurol Taiwan. 2009;18:81-90.

62. Bohlega S, Al Shubili A, Edris A, et al. CADASIL in Arabs: clinical and genetic findings. BMC Med Genet. 2007;8:67.

63. Dong Y, Hassan A, Zhang Z, Huber D, Dalageorgou C, Markus HS. Yield of screening for CADASIL mutations in lacunar stroke and leukoaraiosis. Stroke. 2003;34:203-205.

64. Reyes S, Viswanathan A, Godin O. Apathy: a major symptom in CADASIL. Neurology. 2009;72:905-910.

65. Feuerhake F, Volk B, Ostertag CB. Reversible coma with raised intracranial pressure: an unusual clinical manifestation of CADASIL. Acta Neuropathol (Berl). 2002;103:188-192.

66. Kalimo H, Ruchoux MM, Viitanen M, Kalaria RN. CADASIL. A common form of hereditary arteriopathy causing brain infarcts and dementia. Brain Pathol. 2002;12:371-384.

67. Delibas S, Guven H, Comoglu SS. A case report about CADASIL: mutation in the NOTCH3 receptor. Acta Neurol Taiwan. 2009;18: 262-266.

68. Buffon F, Porcher R, Hernandez K, et al. Cognitive profile in CADASIL. J Neurol Neurosurg Psychiatry. 2006;77:175-180.

69. Kalimo H, Viitanen M, Amberla K, et al. CADASIL: hereditary disease of arteries causing brain infarcts and dementia. Neuropathol Appl Neurobiol. 1999;25:257-265.

70. Yin X-Z, Ding M-P, Zhang B-R, et al. Report of two Chinese families and a review of mainland Chinese CADASIL patients. $J$ Neurol Sci. 2009;279:88-92.

71. Santa Y, Uyama E, Chui DH, et al. Genetic, clinical and pathological studies of CADASIL in Japan: a partial contribution of NOTCH3 mutations and implications of smooth muscle cell degeneration for the athogenesis. J Neurol Sci. 2003;212:79-84.

72. Mykkänen K, Junna M, Amberla K, et al. Different clinical phenotypes in monozygotic CADASIL twins with a novel NOTCH3 mutation. Stroke. 2009;40:2215-2218.
Neuropsychiatric Disease and Treatment

\section{Publish your work in this journal}

Neuropsychiatric Disease and Treatment is an international, peerreviewed journal of clinical therapeutics and pharmacology focusing on concise rapid reporting of clinical or pre-clinical studies on a range of neuropsychiatric and neurological disorders. This journal is indexed on PubMed Central, the 'PsycINFO' database and CAS, and is the official

\section{Dovepress}

journal of The International Neuropsychiatric Association (INA). The manuscript management system is completely online and includes a very quick and fair peer-review system, which is all easy to use. Visit http://www.dovepress.com/testimonials.php to read real quotes from published authors. 